\title{
DOING PARTICIPATORY, ACTION, AND COMMUNITY-ENGAGED RESEARCH IN NEOLIBERAL TIMES: INSIGHTS, EXPERIENCES, AND FORMS OF RESISTANCE
}

An Editorial

Marc Spooner

Guest Editor

As the guest editor, I am so pleased to help bring you this current six article special issue. Many thanks to all the authors, the whole Canadian Journal of Action Research [CJAR] team, all of you who have already participated in the sessions that have led up to this issue, and now you too, dear reader.

Choosing what matters over what counts in spite of the audited, managerial academy is a predicament faced by many scholars who adopt a relational stance to knowledge creation and engagement; such approaches include research designs that are participatory, actionoriented, Indigenous, community-centred, and more. How neoliberalism, New Public Management, and audit culture affect these choices was the question we sought to shed light on at the Congress of the Humanities and Social Sciences held at the University of Regina in 2018 when I was invited by the Canadian Association for Action Research in Education (CAARE) - a Special Interest Group of the Canadian Society for Studies in Education (CSSE) - to give a keynote presentation. Later at Congress 2019, held at the University of British Columbia, we would further explore this topic in conversation with expert panelists: Drs. Budd Hall, Marie Battiste, and E. Wayne Ross. The present, similarly themed 2020 special issue of the Canadian Journal of Action Research is the latest instalment in our ongoing dialogue, exploration, and engagement with the topic. Now it is in your hands to engage with, explore, utilize, critique, and make living.

Audit culture and New Public Management, by design, imperil the participatory, critical, subversive, and imaginative possibilities inherent in teaching and research. Broadly, audit culture's aim is to render us as auditable subjects, compelling us to conform to its own (ideological) notions of what counts as scholarship. Specifically, it forcibly steers us to "produce" what can be easily quantified, tabulated, standardized, evaluated, ranked and benchmarked. By leveraging and weaponizing a narrow band of metrics, like total grants, 
journal articles, journal impact factors, and citation counts, whole realms of scholarly endeavour are devalued or left out of the equation altogether. Often these pseudo-evaluation scores then wag the dog as they creep onto our campuses and manifest themselves via subscriptions to costly web-based analytic tools such as Clarivate's "InCites" or Elseviers' "SciVal," which in the company's own words "...allows you to visualize your research performance, benchmark relative to peers, develop strategic partnerships, identify and analyze new, emerging research trends, and create uniquely tailored reports." (https://www.elsevier.com/solutions/scival).

Though these commercial analytics subscription tools are demonstrably misleading, they nevertheless possess a great allure as they present a veneer of objectivity. The issue here of course is that their "objectivity" is falsely derived by employing a narrow and incomplete window into what is in actuality a broad panorama of possible and legitimate scholarly activities and uses. Under this type of audit culture, epistemological approaches that are slow, relational, and/or local in nature, including, action, community-based, participatory, liberatory, Indigenous, arts-based, and political research designs whose end products do not necessarily lead to journal articles are made to seem unworthy since they are uncounted. Moreover, work that does produce a more conventional output, for example, a journal article, but that is collaborative in nature and undertaken at a deliberate and ethical pace is made to appear unproductive given the longer publication time frames required by these additional steps. Additionally, if the research is local in nature, as opposed to international, it will often be cited fewer times given the potential interest pool. It becomes clear that choosing what is right and doing what matters over what "counts" can often put scholars at risk of being left out or trivialized by these and other potentially suffocating metrics in an increasingly audited and surveilled academy. As previously noted in an in-depth exposition of these neoliberal and accountability-focused university transformations, I cautioned,

...as the triple crisis [market, managerialism, measurement] spreads, a vast body of scholarship is arbitrarily legitimized or delegitimized as it is viewed through the distorting lens of narrowly applied metrics and productivity benchmarks. Worryingly, this skewed view constrains not only research designs and output options but also methodological possibility itself. We are forcibly importuned by a new type of managerialism to squeeze our results through a kind of research meat grinder, where outputs must still be measured and accounted for by the tired and broken weigh-scale of traditional metrics (i.e., journal articles, impact factors, grants sizes) regardless of how inappropriate, unethical (Stiegman \& Castleden, 2015), limiting (Lincoln, 2012; Spooner, 2015a), or insignificant such narrow conceptions of scholarship and impact may be to ourselves and our communities. (Spooner, 2018, p. 898)

At this point, it may be useful to review a few key concepts such as neoliberalism, New Public Management, and audit culture. 


\section{KEY BACKGROUND CONCEPTS \\ Neoliberalism}

The term 'neoliberalism' is employed to describe a wide variety of phenomena - diminishing its precision as well as its utility - but in its present usage, at neoliberalism's theoretical core is:

...a rearticulation and reconfiguration of the eighteenth and nineteenth century liberalist argument that market exchange captures an essential and basic truth about human nature and the creation and maintenance of social order (Dean, 1999: 159; Harvey, 2005). As such, it should become the model for conducting and managing a host of activities that were previously deemed "outside of" or "above" the intrusion of the marketplace.... This new "greater good" was seen as being brought about not through cooperation and the governmental leveling mechanisms of the past but through the self-interested activities of actors each working independently and unknowingly ... empowered consumers-citizens and taxpayers whose desires and self-interest would lead them to demand low costs, accountability and transparency from all of those who provided them with products and services, including the state. (Ward, 2012, pp. 2-3)

\section{New Public Management}

The changing manner by which postsecondary education is conceptualized and delivered is directly related to the widespread shift to New Public Management techniques which seek to operationalize a neoliberal ideology; these changes include: (a) adopting private-sector management practices; (b) introducing market-style incentives and disincentives; (c) introducing a customer orientation coupled with consumer choice and branding; (d) devolving budget functions while maintaining tight control through auditing and oversight; (e) outsourcing labour with casual, temporary staff; and (f) emphasising greater output performance measures and controls in the name of efficiency and accountability (Lapsley, 2009; Lorenz, 2012; Ward, 2012).

\section{Audit Culture}

Schwandt (2015) characterises audit culture as being

...closely associated with neoliberal theories of governance and the reform ideology of New Public Management (NPM). The general thrust of the reform is to improve the efficiency and performance of public sector organizations by making services more responsive to users or consumers, applying private-sector management techniques with a strong focus on benchmarking and measured performance, and creating a performance-oriented culture in the public sector. (p. 9)

Alarmingly, it is difficult to find any university, anywhere, untouched by the confluence of these inextricably linked, interdependent, and mutually reinforcing developments though the specific nature of these changes is dependent on governmental structures, traditions, and local contexts. 
Canadian universities, until recently, had been largely spared provincially-imposed market and regulatory restructuring, such as those that take place under performance-based funding models.

\section{All That Has Changed Now}

However, by early 2020, all that changed when both Ontario and Alberta provincial governments announced that they would impose performance-based funding models onto their universities. The details concerning the exact number and nature of the metrics to be used remain ill-defined as they have been recalled and modified several times since their respective initial announcements. That being said, it is clear, the proposed indicators in both provinces for determining how well universities are performing (and thus funded) will be heavily linked to labour, economic, and corporate sector outcomes. Metrics such as industryfunded research and Tri-Council funding are of particular interest and concern for researchers who engage in non-conventional approaches and designs; this is especially the case for research that requires little or no funding, and/or is rooted in community.

For administrators, since the proportion of operating funding will be increasingly tied to performance against such indicators, the temptation will be great to use these same metrics to evaluate individual performance. The Canadian Association of University Teachers (CAUT) cautions,

Academic work is best assessed through peer review and not by performance metrics. Reliance on performance metrics can violate academic freedom, interfere with collegial governance, hiring, tenure and promotion decisions, compensation, working conditions, and disciplinary actions. Measuring research output with an exclusive or excessive emphasis on performance metrics neglects the diversity and totality of scholarly activity. Performance metrics can especially disadvantage Aboriginal scholars, members of equity-seeking groups, those publishing or disseminating knowledge in languages other than English, those who are on non-traditional career paths, as well as those who conduct unconventional research and/or use nontraditional research methods. (https://www.caut.ca/content/performance-metrics)

Inevitably, performance metrics shape research and teaching agendas as universities, units, programs, and individual performance are, in one form or another, ranked against them and funded accordingly.

Metrics, such as those put forth by the Ontario and Alberta governments, which include "Industry funded research," "Research capacity," "Sponsored research," and "Tri-Council funds" begin to reveal an inherent bias in equating research capacity, innovation, and value with the simple calculus of total funds and share percentage received. Such indicators privilege the types of research that fit into established funding envelopes and conventional output formats, while devaluing non-conventional scholarship; for example, communityengaged, participatory, and Indigenous research approaches to name but a few. Overlooked altogether is potentially highly impactful work that requires time, commitment, trust, and relationship building, yet little funding, or whose funding may be sourced, not through industry, but via a variety of communities or individuals. 
Performance-based funding models, as they have been operationalized by Ontario and Alberta, with a heavy focus on labour-market outcomes and awarded sponsored funds seem intent on devolving university campuses into training centres dedicated to churning out atomized workers and market-focused scholarship. They further coerce the traditional university away from its aspirational ideals of being an accessible institution dedicated to fostering critical, creative, and engaged citizens and which generates research and engagement in the public interest and to the primary benefit of our communities. Bluntly, if the performance-based funding dominoes continue to topple in the direction in which they are currently heading, Canadian scholars are in for the fight of their careers. And yet, as bleak as the view ahead may seem, just over the horizon there are rays of hope inviting us to illuminate alternate paths. There are reasons to be optimistic. Journal special issues like this one which celebrate neoliberal resistance and scholarly diversity are also present.

On this optimistic note, if it is truly the case (and dearly I hope it is) that as Clausen and Black (2020) exclaim, "there is a future for action research in this country" (p. 3), then it is upon us, as a community of scholars, to re-affirm and re-assert our inherent and rightful legitimacy and scholarly presence. The recent 2020 publication of Clausen and Black's edited collection The Future of Action Research in Education: A Canadian Perspective is certainly another bright spot; an additional positive sign can be found in the joint statement issued on November 13, 2019 by Canada's five major national research funders (Canadian Institutes of Health Research, Natural Sciences and Engineering Research Council, Social Science and Humanities Research Council, Canada Foundation for Innovation, and Genome Canada) recognizing:

The quality and impact of research cannot be measured through journal publications alone. Research results and outcomes are multifaceted, can reflect multiple types of knowledge and ways of knowing and must be assessed on their own merit. Highquality research outcomes are achieved in many ways, including but not limited to: publishing research articles; reporting new knowledge (such as presenting at conferences and other venues); developing new technologies, producing software and intellectual property; sharing data; contributing to policy decisions; producing highly trained personnel and working in partnership with various sectors of society. Increasingly, funding agencies, research institutions, First Nations, Inuit and Métis communities, citizens and patients, and researchers themselves, agree on the importance of including a broader set of research outcomes and adopting assessment processes that recognize their value."1

\section{REVIEWING THE CURRENT SPECIAL ISSUE}

The first two papers presented in this special issue provide a wide-angle philosophical overview allowing us to examine the roots and manifestations of neoliberalism, colonization, and epistemic justice.

In E. Wayne Ross' paper entitled, "Why Are Things As They Are? Action Research and the Transformation of Work and Education in the Neoliberal Age," he points out how we are as

\footnotetext{
${ }^{1}$ See https://www.nserc-crsng.gc.ca/Media-Media/NewsDetail-DetailNouvelles_eng.asp?ID=1103
} 
fish swimming in neoliberalism, and similarly often unaware of the medium in which we are immersed. Ross warns of the danger when participatory approaches are co-opted by researchers, consultants, and others, and subverted into a form of social regulation that supports and sustains neoliberal accumulation and the coloniality of power. He cautions,

Contemporary schools and universities are defined by bureaucratic outcomes-based accountability, audit culture, performance-based funding, surveillance technologies, automation, bullying, mobbing, casualization, precarity, intensification, fragmentation, segmentation, gentrification of criticism and dissent, all of which create (academic) stress and feed into attacks on academic freedom, free speech, and faculty solidarity, as well as the creation of the all administrative university (Ginsberg, 2011). To understand the nature of schools and universities, to navigate their waters, and to re-imagine the ecosystem of learning, teaching, and researching, we have to understand how neoliberalism defines our institutions, work, goals, and our very lives." (p. 12)

In "Knowledge Democracy and Epistemic In/Justice: Reflections on a Conversation," Budd L. Hall, Baptiste Godrie, and Isabel Heck walk us through their three-way discussion examining discourses of knowledge democracy, epistemic inequalities, and cognitive imperialism. Their conversation is naturally informed by their respective vantage points, Budd Hall as the Co-Chair of the UNESCO Chair in Community-Based Research, Baptiste Godrie as affiliated with Le Centre de recherche de Montréal sur les inégalités sociales (CREMIS), and Isabel Heck with Parole d'excluEs (both organisations are communityuniversity research partnerships). They ask "How is knowledge created? Who creates knowledge? How is knowledge co-constructed? Whose knowledge is excluded and how is knowledge being used to challenge inequalities and strengthen social movement capacity?"

The next two articles that follow in the special issue share the barriers, challenges, and successes with research that is participatory and community-based. The first examines land wars and PAR initiatives in India from a Freirian and oppositional politic as they have been involved with social movements over the last two decades. The next article, set primarily on Treaty 6 Territories, takes up PAR from a long-term community collaboration employing a community-based participatory arts and research approach.

In "Neoliberal Colonial Capital and Participatory Action Research (PAR) in Terrains of Land/Forest-Based Resistance," Dip Kapoor reminds us that neoliberal capitalism is the contemporary manifestation of a continued process of neocolonial and internal colonial penetration. His paper examines neoliberal colonial capitalist dispossession in India and its colonial antecedents and elaborates on "...the dialectical relation between neoliberal landforest dispossession and rural resistance, including the role of Participatory Action Research (PAR) with/in these terrains of land/forest-based activisms in the east-coast state of Odisha" where "over a period of two decades, PAR has been enacted as a process of social movement, learning and organizing..." (p. 47-48). 
Michelle Stewart, Rebecca Caines, and Andrea Kotlar-Livingston in "On Neoliberal Thirst, Audit Hunger, and Sustaining Strengths-Based Research in Community and Academy," detail their experiences with formulating a collaborative and participatory experimental music improvisation program together with people with Fetal Alcohol Spectrum Disorders (FASD), as well as their difficulties with reporting this research within a restrictive academy. The authors sought to capture the untapped creativity of people with FASD, such as capacity for fluid improvisation. Here deficits of FASD are reconfigured in an artistic space to capture creativity and lived experience. They share,

From a modest pilot project of eight sessions with 50 participants, the project has grown significantly and unexpectedly as the toolkit has been tested and demonstrated face-to-face with over seven hundred individuals across Canada, Australia, Northern Ireland and the United States. It has been transformed into a resource supporting peer workshops lead by individuals with FASD. (p. 79)

The final two papers examine neoliberal effects on learning and education in informal, nonformal, and formal settings. The penultimate paper in this collection looks at how schools, as formal education settings, have been imbued with neoliberal traits even at the kindergarten level. In "Masquerade of Neoliberal Concepts Revealed: Self-regulation Skills in Ontario's Full Day Kindergarten Program," Manu Sharma reports on a practitioner based action research project that included four kindergarten teachers in Ontario's full day programs. Sharma shares how they, as teachers, were expected to

use self-regulation to eliminate in-class fighting, bullying, and aggressive behaviour. However, through reflection and analysis in this action research project.... [Sharma] noticed that self-regulation practices as part of [Full Day Kindergarten] match neoliberal traits that have become predominant in education today. (p. 89)

In the special issue's final featured paper, "Engaging Youth to Explore Activism: An Educational Framework for Supporting an Ecological Justice-Oriented Citizenry," Karen McIver $^{2}$ shares an action research project that involved creating live radio segments with youths. These live shows served as a vehicle for mentored learning experiences that nurtured youth activist identities and fostered steps towards a justice-oriented citizenship. McIver's research sought to

...investigate the role place has played in maintaining the identities of activists committed to social and ecological justice. The secondary focus of the research was to examine whether youth involvement in a participatory, critical learning experience of creating live radio shows with activists as their guests helped the youth to develop and maintain their own activist identity and community. (p. 103)

\footnotetext{
2 Conflict of Interest Statement: Karen McIver is my partner, however, to be absolutely clear all of the manuscripts included in this issue have been subjected to the same rigorous double-blind peer-review process including Karen Mclver's submission.
} 


\section{CONCLUSION}

It is my profound hope that readers will enjoy these varied and insightful pieces as much as I did; more importantly, I hope that we, as a scholarly collective, take up battle to enact the various forms of resistances crucially highlighted in these works. It is truly ironic that just as many of these alternative, relational, and community-based approaches are finally finding their bearings, the ground on Canadian campuses is moving out from under them as our universities are destabilized by the adoption of performance-based funding models. Indeed, it is no accident that performance-based funding schemes are coming to the fore as Canadian universities are being forced to compete for a diminishing pool of dollars and governments with illiberal tendencies wish to stifle organization, critique, and dissent. The highereducation sector as a whole must recognize that such funding models erode solidarity not only between universities but between individual scholars. Creating winners and losers encourages us to attribute blame on ourselves for any failure to measure up, however inadequate and misleading the metrics may be. How insidious? It is certainly time to reaffirm and strengthen our collegial governance structures and to acknowledge that our unions are increasingly taking up the work to protect the aspirational ideals of the academy. Onward and upward...

\section{REFERENCES}

Clausen, K. W., \& Black, G. L. (Eds.) (2020). The future of action research in education: $A$ Canadian perspective. Montreal, QC \& Kingston, ON: McGill-Queen's University Press.

Lapsley, I. (2009). New Public Management: The cruellest invention of the human spirit? Abacus: A Journal of Accounting Finance and Business Studies, 45, 1-21.

Lorenz, C. (2012). If you're so smart, why are you under surveillance? Universities, neoliberalism, and New Public Management. Critical Inquiry, 38, 599-629.

Schwandt, T. A. (2015). The SAGE dictionary of qualitative inquiry (4th ed.). Thousand Oaks, CA: SAGE.

Spooner, M. (2018). Qualitative research and global audit culture: The politics of productivity, accountability, and possibility. In N. K. Denzin \& Y. S. Lincoln (Eds.), Handbook of qualitative research (5th ed., pp. 894-914). Thousand Oaks, CA: SAGE.

Ward, S. C. (2012). Neoliberalism and the global restructuring of knowledge and education. New York: Routledge. 


\section{BIOGRAPHICAL NOTE:}

Marc Spooner is a professor in the Faculty of Education at the University of Regina. He specializes in qualitative research at the intersections of theory and action on the ground. His interests include audit culture and the effects of neoliberalization and corporatization on higher education; and social justice, activism, and participatory democracy. He has published in many venues, including peer-reviewed journals, book chapters, government reports, and a wide variety of popularizations. Together with colleagues at the University of Regina, he also co-hosts a popular education series that takes place in pubs-not on campus-entitled 'Talkin' about School and Society'. He is oftentimes a social/political commentator who can be followed on Twitter here: @drmarcspooner 